\title{
Characterization and comparison of Pasteurella multocida strains associated with porcine pneumonia and atrophic rhinitis
}

\author{
Robert L. Davies, Roslyn MacCorquodale, Susan Baillie and Bridget Caffrey
}

Correspondence

Robert L. Davies

r.l.davies@bio.gla.ac.uk

Received 5 July 2002

Accepted 15 September 2002
Division of Infection and Immunity, Institute of Biomedical and Life Sciences, Joseph Black Building, University of Glasgow, Glasgow G12 800, UK

\begin{abstract}
One hundred and fifty-eight porcine strains of Pasteurella multocida, recovered primarily from cases of pneumonic pasteurellosis or progressive atrophic rhinitis (PAR) in England and Wales, were characterized by determination of their capsular types, presence or absence of the tox $A$ gene and molecular mass heterogeneity of the heat-modifiable $(\mathrm{OmpA})$ and porin $(\mathrm{OmpH})$ proteins. Eighteen groups (clones) of strains were identified on the basis of specific combinations of capsular type, tox $A$ status and outer-membrane protein (OMP)-type. The data provided evidence that different subpopulations of $P$. multocida are responsible for pneumonia and PAR in pigs. The majority ( $88 \%$ ) of cases of pneumonia were associated exclusively with non-toxigenic capsular type $A$ strains of OMP-types 1.1, 2.1, 3.1 and 5.1 and capsular type $D$ isolates of OMP-type 6.1. These strains were recovered from widespread geographical locations within England and Wales over a 12-year period and represented mostly single sporadic cases. The association of a small number of $P$. multocida variants with the majority of cases of porcine pneumonia suggests that these strains are not opportunistic pathogens of low virulence but represent primary pathogens with a relatively high degree of virulence. In contrast, the majority (76\%) of cases of PAR were associated with toxAcontaining capsular type D strains of OMP-type 4.1 and capsular type $A$ and $D$ strains of OMP-type 6.1. Toxigenic capsular type $A$ strains associated with PAR and non-toxigenic capsular type $A$ strains associated with pneumonia represent distinct subpopulations of $P$. multocida that can be differentiated by their OMP-types. The association of capsular types $A$ and $D$ with strains of the same OMP-types, and the absence and presence of the tox $A$ gene in strains of the same OMP-types, suggest that horizontal transfer of capsular biosynthesis and tox $A$ genes has occurred between strains representing certain subpopulations of $P$. multocida.
\end{abstract}

\section{INTRODUCTION}

Pasteurella multocida is the aetiological agent of progressive atrophic rhinitis (PAR) of swine and is of considerable economic importance to the pig-rearing industry throughout the world (Chanter \& Rutter, 1989). PAR is characterized by atrophy of the nasal turbinate bones which, in severe cases, can lead to facial distortion. P. multocida strains associated with PAR usually produce a $145-\mathrm{kDa}$ dermonecrotic toxin, which is encoded by the toxA gene (Lax et al., 1990; Buys et al., 1990). This toxin induces osteolysis in the turbinate bones and plays an important role in the pathogenesis of PAR (Kamp \& Kimman, 1988). Toxigenic strains associated with PAR are most frequently of capsular type D (Eamens et al., 1988; Foged et al., 1988; Gardner et al., 1994; Lariviere et al., 1992), although toxigenic isolates of capsular type A can also be involved in the disease (Fussing et al., 1999; Sakano et al.,

Abbreviations: OMP, outer-membrane protein; PAR, progressive atrophic rhinitis.
1992). Non-toxigenic P. multocida strains are not usually associated with PAR and confirmation of toxin production is important for the diagnosis and control of the disease (Bowersock et al., 1992).

P. multocida is also frequently isolated from the lungs of pneumonic pigs and is thought to play a central role in porcine pneumonic pasteurellosis (Pijoan et al., 1983, 1984; Pijoan, 1992; Rubies et al., 2002; Zhao et al., 1992). Prior infection with other micro-organisms such as pseudorabies virus and Mycoplasma hyopneumoniae predisposes pigs to secondary infection with P. multocida (Ciprian et al., 1988; Fuentes \& Pijoan, 1987). In contrast to isolates associated with PAR, P. multocida strains isolated from pneumonic lungs are usually non-toxigenic and of capsular type A (Pijoan et al., 1983, 1984; Rubies et al., 2002; Zhao et al., 1992). However, a small proportion of lung isolates are toxigenic and/or possess capsular type D (Pijoan et al., 1984; Rubies et al., 2002; Choi et al., 2001). 
Despite the obvious differences between pneumonia and PAR and their association with P. multocida strains of different capsular types and toxin status, very little is known about the relationships of isolates responsible for each of these diseases (Djordjevic et al., 1998). A number of different methods such as bacteriophage typing, plasmid profiling, restriction endonuclease analysis, ribotyping and analysis of outer-membrane proteins (OMPs) have been used to examine diversity among $P$. multocida strains associated with either PAR (Gardner et al., 1994; Fussing et al., 1999; Harel et al., 1990; Donnio et al., 1999; Nielsen \& Rosdahl, 1990; Lugtenberg et al., 1984; Vasfi Marandi \& Mittal, 1995; Bowles et al., 2000) or pneumonia (Rubies et al., 2002; Zhao et al., 1992; Blackall et al., 2000). However, there have been very few comparative studies of $P$. multocida isolates derived from both PAR and pneumonia (Djordjevic et al., 1998).

The OMPs of Gram-negative bacteria play essential roles in host-pathogen interactions and in disease processes (Lin et al., 2002). These proteins are at the interface between pathogen and host and are subject to various selective pressures depending on their function. Consequently, OMPs exhibit varying degrees of inter-strain heterogeneity and this can be used to assess intra-species diversity and determine epidemiological relationships. The heat-modifiable and porin proteins are important classes of OMPs that are surface-exposed and exhibit molecular mass and antigenic variation (Sikkema \& Murphy, 1992; Duim et al., 1997). P. multocida expresses heat-modifiable (OmpA) and porin $(\mathrm{OmpH})$ proteins on the cell surface (Lugtenberg et al., 1984; Vasfi Marandi \& Mittal, 1996, 1997; Luo et al., 1997, 1999; Vasfi Marandi et al., 1996), but very little is known about the precise roles of these proteins in pathogenesis. Heterogeneity of the $\mathrm{OmpH}$ protein in somatic serotype strains of $P$. multocida is due to the presence of hypervariable surface-exposed loop regions (Luo et al., 1999). In addition, the $\mathrm{OmpH}$ protein provides protection against $P$. multocida challenge in mice (Vasfi Marandi \& Mittal, 1997) and chickens (Luo et al., 1999) and has potential as a vaccine candidate. However, very little is known about OmpA and $\mathrm{OmpH}$ heterogeneity among porcine $P$. multocida strains associated with PAR and pneumonia.

The aim of the present study was to characterize porcine strains of $P$. multocida recovered from cases of pneumonia and PAR by comparative analysis of their capsular types, tox $A$ status and OMP profiles. In particular, molecular mass heterogeneity of the OmpA and $\mathrm{OmpH}$ proteins was examined and used as the basis of an OMP classification scheme to assess, in conjunction with toxA status and capsular type, inter-strain relatedness among porcine $P$. multocida isolates.

\section{METHODS}

Bacterial strains and growth conditions. One hundred and fiftyeight porcine strains of $P$. multocida were investigated in this study. The isolates were obtained from regional laboratories of the UK Veterinary Laboratories Agency (VLA) and originated from widespread geogra- phical locations within England and Wales over a 12-year period (19892000). The strains were recovered from 125 cases of porcine pneumonia and 17 cases of PAR or suspected PAR. Sixteen isolates were associated with a variety of miscellaneous or unknown symptoms. The identification of strains at the veterinary laboratories was based on clinical symptoms and pathology, isolation in pure culture and routine bacteriological tests. The capsular reference strains X73 (capsular type A), M1404 (B), P3881 (D), P1235 (E) and P4679 (F) were kindly provided by Dr R. Rimler (National Animal Disease Center, Ames, IA, USA). Properties of the isolates are given in Table 1.

The isolates were stored at $-85^{\circ} \mathrm{C}$ in $50 \%(\mathrm{v} / \mathrm{v})$ glycerol in brain heart infusion broth (BHIB). From $-85^{\circ} \mathrm{C}$ stock cultures, bacteria were streaked onto blood agar [brain heart infusion agar containing $5 \%(\mathrm{v} / \mathrm{v})$ defibrinated sheep blood] and incubated overnight at $37^{\circ} \mathrm{C}$. For preparation of DNA, a few colonies were inoculated into $10 \mathrm{ml}$ volumes of BHIB and grown overnight at $37^{\circ} \mathrm{C}$ at 120 r.p.m. For preparation of outer membranes, $0.4 \mathrm{ml}$ of overnight growth in BHIB was inoculated into $400 \mathrm{ml}$ volumes of BHIB in 21 Erlenmeyer flasks and incubated for $7 \mathrm{~h}$ at $37^{\circ} \mathrm{C}$ at 120 r.p.m.

Preparation of chromosomal DNA. Cells from $1.0 \mathrm{ml}$ overnight culture were harvested by centrifugation for $1 \mathrm{~min}$ at $13000 \mathrm{~g}$ and washed once in sterile, distilled water. DNA was prepared with the InstaGene matrix (Bio-Rad) according to the manufacturer's instructions and stored at $-20^{\circ} \mathrm{C}$.

Capsular PCR typing. The capsular types were determined by multiplex capsular PCR typing (Townsend et al., 2001). Capsulespecific primers (CAPA, CAPB, CAPD, CAPE and CAPF) were synthesized by Sigma-GenoSys (Cambridge, UK) and the capsular gene fragments were amplified with a Taq DNA polymerase kit (Boehringer Mannheim) according to the manufacturer's instructions. PCRs were carried out in a GeneAmp PCR System 9700 thermal cycler (Applied Biosystems) using the following amplification parameters: denaturation at $94{ }^{\circ} \mathrm{C}$ for $30 \mathrm{~s}$, annealing at $58{ }^{\circ} \mathrm{C}$ for $30 \mathrm{~s}$ and extension at $72{ }^{\circ} \mathrm{C}$ for $1 \mathrm{~min}$. Thirty cycles were performed and a final elongation step of $72{ }^{\circ} \mathrm{C}$ for 10 min was used. Production of PCR amplicons of the expected sizes was confirmed by electrophoresis and ethidium bromide staining in $2 \%$ agarose gels. Pooled PCR amplicons of serotype A, B, D, E and F reference strains were used as internal size standards in each gel. Strains that were negative for all five capsular types were confirmed as being $P$. multocida in separate PCR assays with a P. multocida-specific primer set (Townsend et al., 2001) and classified as untypable.

PCR detection of the toxA gene. Detection of the toxA gene was carried out by PCR as described previously (Lichtensteiger et al., 1996) with the exception that different oligonucleotide primers were used. The primers were designed after alignment and comparison of published toxA sequences (Lax et al., 1990; Buys et al., 1990; Petersen, 1990). The oligonucleotide primers were designed to amplify a $1854 \mathrm{bp}$ fragment of toxA between nucleotides 2190 and 4043 (Petersen, 1990); the forward primer was $5^{\prime}$-CGTGAACTGCGTACTCAA-3' and the reverse primer was $5^{\prime}$-AAGAGGAGGCATGAAGAG-3'. PCR amplification of the toxA gene fragment was carried out as described above for capsular PCR typing except that an annealing temperature of $56^{\circ} \mathrm{C}$ for $30 \mathrm{~s}$ was used. Production of PCR amplicons of the expected size was confirmed by electrophoresis and ethidium bromide staining in $1 \%$ agarose gels. A $1 \mathrm{~kb}$ DNA ladder (Gibco Life Technologies) was used to size the fragments. The PCRs were carried out twice.

Preparation of OMPs. Outer membranes were prepared by Sarkosyl extraction as described previously (Davies et al., 1992; Davies \& Donachie, 1996). The protein concentrations were determined by the modified Lowry procedure (Markwell et al., 1978) and the OMPs were adjusted to $2 \cdot 0 \mathrm{mg} \mathrm{ml}^{-1}$ in $20 \mathrm{mM}$ Tris/ $\mathrm{HCl}(\mathrm{pH} \mathrm{7 \cdot 2)}$ and stored at $-85^{\circ} \mathrm{C}$. 
Table 1. Properties of porcine strains of $P$. multocida

\begin{tabular}{|c|c|c|c|c|}
\hline OMP-type & $\begin{array}{c}\text { Capsular } \\
\text { type }\end{array}$ & $\begin{array}{c}\text { toxA } \\
\text { status }\end{array}$ & $\begin{array}{c}\text { Strains } \\
(n)\end{array}$ & Clinical symptoms (no. of strains) \\
\hline 1.1 & A & - & 62 & Pneumonia (57); septicaemia (3); other (2) \\
\hline \multirow[t]{2}{*}{1.2} & A & - & 1 & Unknown \\
\hline & $\mathrm{D}$ & - & 2 & Pneumonia \\
\hline 2.1 & A & - & 12 & Pneumonia (11); PAR (1) \\
\hline 3.1 & A & - & 24 & Pneumonia (20); PAR (1); death (1); coughing (1); unknown (1) \\
\hline \multirow[t]{2}{*}{3.2} & A & - & 3 & Pneumonia (2); PAR (1) \\
\hline & $\mathrm{F}$ & - & 2 & Pneumonia \\
\hline \multirow[t]{3}{*}{4.1} & A & - & 2 & Pneumonia \\
\hline & $\mathrm{D}$ & + & 4 & Pneumonia (1); suspected PAR (2); unknown (1) \\
\hline & UT & - & 2 & Pneumonia \\
\hline \multirow[t]{2}{*}{4.2} & A & - & 1 & Pneumonia \\
\hline & $\mathrm{D}$ & - & 1 & PAR \\
\hline 5.1 & A & - & 8 & Pneumonia (6); other (2) \\
\hline \multirow[t]{3}{*}{6.1} & A & + & 4 & Pneumonia (2); PAR (1); suspected PAR (1) \\
\hline & $\mathrm{D}$ & - & 23 & Pneumonia (16); PAR (4); pleurisy (1); other (2) \\
\hline & $\mathrm{D}$ & + & 5 & PAR (2); suspected PAR (3) \\
\hline \multirow[t]{2}{*}{6.2} & A & + & 1 & Unknown \\
\hline & $\mathrm{D}$ & - & 1 & Pneumonia \\
\hline
\end{tabular}

UT, Untypable.

SDS-PAGE. The OMPs were separated by SDS-PAGE in $12 \%(\mathrm{w} / \mathrm{v})$ resolving gels (Hoefer SE600 electrophoresis apparatus) using the SDS discontinuous system of Laemmli (1970) as described previously (Davies et al., 1992; Davies \& Donachie, 1996). Unless otherwise stated, all samples were heated at $100{ }^{\circ} \mathrm{C}$ for $5 \mathrm{~min}$ prior to electrophoresis. Twenty micrograms of protein were loaded per lane and the proteins were visualized by staining with Coomassie brilliant blue. Protein molecular mass standards (Pharmacia) consisted of phosphorylase b $(94 \mathrm{kDa})$, BSA $(67 \mathrm{kDa})$, ovalbumin $(43 \mathrm{kDa})$, carbonic anhydrase $(30 \mathrm{kDa})$, trypsin inhibitor $(20 \cdot 1 \mathrm{kDa})$ and $\alpha$-lactalbumin $(14 \cdot 4 \mathrm{kDa})$. The molecular masses of individual proteins were calculated with the Labworks image acquisition and analysis computer software.

\section{RESULTS}

\section{Capsular PCR typing}

Capsular PCR analysis resulted in the amplification of a single band representing serogroup-specific regions of the biosynthetic loci in all of the isolates except for two (results not shown). The size of each PCR fragment corresponded exactly to that of one of the reference strains A (1044 bp), D (657 bp) or F ( $851 \mathrm{bp}$ ) and allowed the capsular type to be determined (Townsend et al., 2001). The two untypable isolates were confirmed as being $P$. multocida in separate PCR assays with $P$. multocida-specific primers. The distribution of capsular types among the 158 porcine $P$. multocida isolates is shown in Table 1 . One hundred and eighteen $(75 \%)$ strains were of capsular type A, 36 (23\%) were of capsular type D, two $(1 \%)$ were of capsular type $\mathrm{F}$ and two $(1 \%)$ were untypable.

\section{PCR detection of the toxA gene}

Successful amplification of the toxA gene resulted in a PCR fragment of the expected size (1854 bp) (Fig. 1). The toxA gene was detected in $14(9 \%)$ isolates. However, toxA was associated exclusively with four groups of strains that could be distinguished by their OMP and capsular types (Table 1).

\section{Analysis of OMP profiles}

The stability of the OMP profiles was examined by comparing the profiles of two strains after repeated subculture and at different stages of the growth cycle. The profiles of these strains were identical after 5, 10, 15 and 20 rounds of subculture on blood agar and after 6, 8, 12 and $24 \mathrm{~h}$ of growth in BHIB (results not shown). The OMP profiles of the 158 strains were provisionally assigned to OMP-types based on profile similarity in SDS-PAGE gels (described below). Strains assigned to the same OMP-type were subsequently rerun on up to three or four occasions so that strains of the same OMP-type were compared directly on the same gel. An OMP classification scheme was devised based, firstly, on molecular mass variation of the two major proteins, OmpA and $\mathrm{OmpH}$ (OMP-type 1, 2, etc.), and, secondly, on variation of minor OMPs (OMP-type 1.1, 1.2, etc.).

The OmpA and $\mathrm{OmpH}$ proteins have overlapping molecular mass ranges $(33-38 \mathrm{kDa})$ and were distinguished on the basis of their different behaviours in SDS-PAGE gels after heat treatment. The $\mathrm{OmpH}$ porin protein is tightly associated with peptidoglycan and does not migrate into the gel unless 


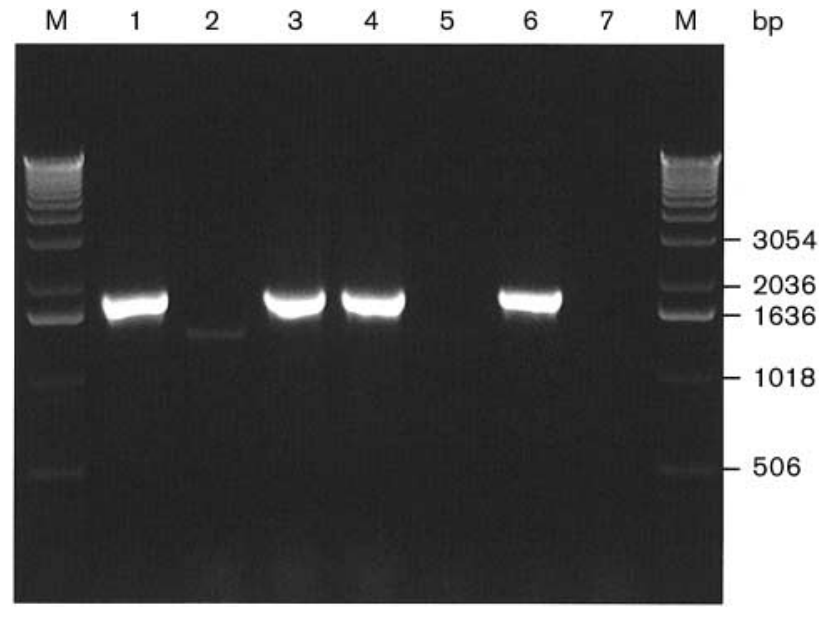

Fig. 1. Ethidium bromide-stained agarose gel showing positive and negative results of PCR amplification of the tox $A$ gene in seven porcine $P$. multocida strains representing various $\mathrm{OMP} /$ capsular types (see Table 1), Lanes: 1, 4.1/D (tox $\left.A^{+}\right) ; 2,4.1 / A\left(\right.$ tox $\left.A^{-}\right) ; 3,6.1 / A$ (tox $\left.A^{+}\right) ; 4,6.1 / \mathrm{D}\left(\right.$ tox $\left.A^{+}\right) ; 5,6.1 / \mathrm{D}\left(\right.$ tox $\left.A^{-}\right) ; 6,6.2 / \mathrm{A}\left(\right.$ tox $\left.A^{+}\right) ; 7,6.2 / \mathrm{D}$ (tox $\left.A^{-}\right) ; M$, size standards.

heated at a temperature of approximately $60{ }^{\circ} \mathrm{C}$ or higher prior to SDS-PAGE (Rosenbusch, 1974). Conversely, the OmpA protein is not associated with peptidoglycan and migrates freely into the gel after heat treatment at temperatures below $60{ }^{\circ} \mathrm{C}$. However, the OmpA protein undergoes a characteristic conformational change when heated at $100{ }^{\circ} \mathrm{C}$ that results in an increase in its apparent molecular mass (Beher et al., 1980). Therefore, to identify OmpA and OmpH, one strain representing each OMP-type was subjected to heat treatment at $50,60,70,80,90$ and $100{ }^{\circ} \mathrm{C}$ for 5 min prior to SDS-PAGE. The results for two strains of OMP-types 4.1 and 5.1 are shown in Fig. 2.
The OMP profiles of the 158 isolates were typical of Gramnegative bacteria and consisted of two major proteins, OmpA and $\mathrm{OmpH}$, and $20-30$ minor proteins. The strains could be subdivided into six distinct groups that were classified as OMP-types 1-6 based on variation of OmpA and $\mathrm{OmpH}$ (described above). Strains of OMP-types 1, 3, 4 and 6 were further subdivided into OMP-types 1.1 and 1.2, 3.1 and 3.2, 4.1 and 4.2 and 6.1 and 6.2 based on variation of minor proteins. Profiles representing the most abundant OMPtypes, namely 1.1, 2.1, 3.1, 4.1, 5.1 and 6.1, are shown in Fig. 3. The molecular mass of OmpA varied from $36 \cdot 5$ to $37 \cdot 7 \mathrm{kDa}$, whereas that of $\mathrm{OmpH}$ varied from 33.5 to $38 \cdot 1 \mathrm{kDa}$. The distribution of OMP-types among the porcine strains is shown in Table 1 . The majority $(82 \%)$ of strains were represented by just four OMP-types, 1.1 (39\%), $2.1(8 \%)$, $3.1(15 \%)$ and $6.1(20 \%)$, whereas the remaining $18 \%$ of strains were associated with six OMP-types.

\section{Relationship between OMP-types, capsular types, toxA status and clinical symptoms}

Strains representing OMP-types 1.1, 2.1, 3.1 and 5.1 were associated exclusively with capsular type A and comprised $67 \%$ of the total number of isolates. None of these isolates possessed the toxA gene. Eighty-nine per cent of the strains representing these four OMP-types were isolated from the lungs of pneumonic pigs. Two isolates were associated with PAR and the remainder with miscellaneous symptoms. Strains of OMP-types 1.2 and 3.2 accounted for only $5 \%$ of the isolates but were respectively associated with capsular types A and D and A and F. None of these isolates possessed the toxA gene and they were also recovered mainly from cases of pneumonia.

Strains representing OMP-types 4.1 and 4.2 were associated with capsular types A and D, although two isolates of OMPtype 4.1 were classified as untypable. Isolates representing
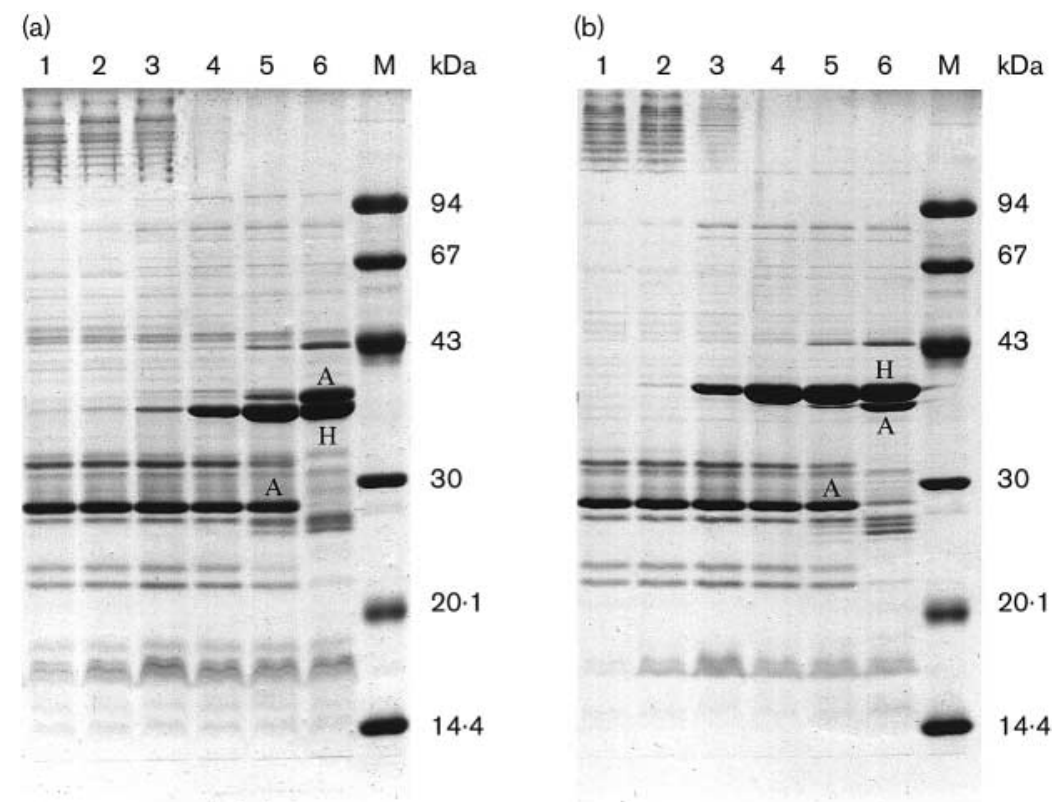

Fig. 2. Coomassie blue-stained SDS-PAGE gels showing the OMP profiles of two P. multocida strains of OMP-types 4.1 (a) and 5.1 (b). The effect of heat treatment on the major $\operatorname{OmpA}(\mathrm{A})$ and $\mathrm{OmpH}(\mathrm{H})$ proteins is clearly seen (see text). The OMP samples were heated at 50,60,70, 80, 90 and $100{ }^{\circ} \mathrm{C}$ (lanes $1-6$, respectively) prior to SDS-PAGE. Lanes M, molecular mass standards. 
these two OMP-types accounted for only $6 \%$ of the total number of strains. All four of the capsular type D strains of OMP-type 4.1 possessed the toxA gene and two of the isolates were associated with suspected PAR. The single capsular type D strain of OMP-type 4.2 was also associated with PAR, but it lacked the toxA gene.

Strains of OMP-type 6.1 represented $20 \%$ of the total number of isolates. Twenty-eight OMP-type 6.1 isolates possessed capsular type D and four strains were of capsular type A. The four capsular type A isolates and five of the capsular type $\mathrm{D}$ isolates possessed the toxA gene. The five capsular type $\mathrm{D}$, tox $A^{+}$strains and two of the capsular type A, tox $A^{+}$strains were associated with PAR. In contrast, the majority $(70 \%)$ of the capsular type $\mathrm{D}$, to $x A^{-}$strains were associated with pneumonia. There were only two isolates representing OMP-type 6.2, one each of capsular types A and D. The capsular type A strain possessed the toxA gene, whereas the capsular type $\mathrm{D}$ isolate did not.

\section{DISCUSSION}

The strains included in this study were confirmed as $P$. multocida based on a positive PCR with primers specific for the capsular biosynthesis genes or with a P. multocidaspecific primer set (Townsend et al., 2001). In addition, selected strains representing the various OMP-types were confirmed as P. multocida by sequence analysis of the $16 \mathrm{~S}$ rRNA gene (unpublished data). The PCR-based capsular typing assay (Townsend et al., 2001) was found to be a rapid and extremely reliable method for determining the capsular types of a large number of $P$. multocida strains. Of 125 isolates associated with pneumonia, $101(81 \%)$ were of capsular type A, $20(16 \%)$ were of capsular type D, two $(1 \%)$ were of capsular type $\mathrm{F}$ and two (1\%) were untypable. The higher proportion of capsular type A strains associated with pneumonia, compared with capsular type D isolates, is in agreement with previous studies (Pijoan et al., 1983, 1984; Rubies et al., 2002; Zhao et al., 1992; Pijoan \& Fuentes, 1987). Capsular type $\mathrm{F}$ and untypable strains are uncommon in pigs, but are often isolated from avian hosts (Rhoades \& Rimler, 1987; Rimler \& Rhoades, 1987; Wilson et al., 1993). However, Choi et al. (2001) identified 21 untypable isolates among 230 P. multocida strains isolated from pneumonic pigs. Of 17 strains associated with PAR, five (29\%) were of capsular type A and $12(71 \%)$ were of capsular type D. The higher proportion of capsular type D strains associated with PAR, compared with capsular type A isolates, is also in agreement with previous studies (Eamens et al., 1988; Foged et al., 1988; Gardner et al., 1994; Lariviere et al., 1992; Sakano et al., 1992). The larger number of isolates associated with pneumonia (125) compared with PAR (17) reflects a higher incidence of pneumonia compared with PAR in England and Wales. A contributing factor towards the relatively low incidence of PAR could be the widespread and successful use of vaccines against this disease.

Genetic diversity of porcine strains of $P$. multocida has been examined in previous studies by restriction endonuclease analysis and ribotyping (Gardner et al., 1994; Fussing et al., 1999; Rubies et al., 2002; Zhao et al., 1992; Djordjevic et al., 1998; Harel et al., 1990; Donnio et al., 1999; Blackall et al., 2000). A comparative analysis of OMP variation in a large population of $P$. multocida strains associated with pneumonia and PAR has not been undertaken. The overall diversity of the OMP profiles was relatively low, since $82 \%$ of the isolates were represented by only four OMP-types, 1.1, 2.1, 3.1 and 6.1. The remaining $18 \%$ of the strains were associated with just six OMP-types. The relatively low degree of diversity of the OMP profiles was not unexpected, because porcine $P$. multocida strains have previously been shown to have limited genetic diversity (Gardner et al., 1994; Fussing et al., 1999; Rubies et al., 2002; Zhao et al., 1992; Harel et al., 1990; Bowles et al., 2000; Blackall et al., 2000). The association of a small number of OMP-types with the majority of the strains suggests that a relatively small number of virulent groups (or clones) are responsible for most cases of infection (discussed in further detail below). These findings are in contrast to the high degree of diversity observed in the OMP profiles of avian isolates of P. multocida (Davies et al., 2003).

The OmpA and OmpH proteins both exhibited molecular mass heterogeneity (Fig. 3), although the molecular mass range of $\mathrm{OmpH}(33 \cdot 5-38 \cdot 1 \mathrm{kDa})$ was greater than that of OmpA $(36 \cdot 5-37 \cdot 7 \mathrm{kDa})$. The shift in molecular mass of

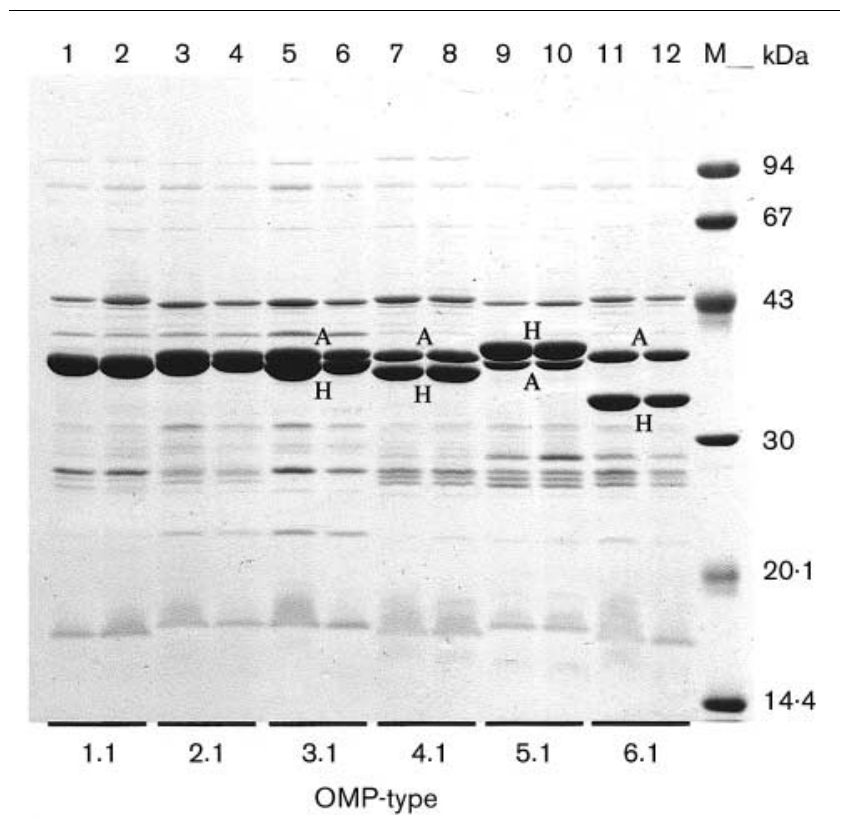

Fig. 3. Coomassie blue-stained SDS-PAGE gel showing representative OMP profiles of porcine $P$. multocida strains after heat treatment at $100{ }^{\circ} \mathrm{C}$. The OMP-types are based on differences in the electrophoretic mobility of the major $\mathrm{OmpA}(\mathrm{A})$ and $\mathrm{OmpH}(\mathrm{H})$ proteins as well as differences in the banding patterns of the minor proteins. The OMP profiles of two strains of each OMP-type are shown to demonstrate reproducibility. The molecular masses of the $\mathrm{OmpA}$ and $\mathrm{OmpH}$ proteins of OMP-types 1.1 to 6.1 are respectively $36 \cdot 5$ and $36 \cdot 5,37 \cdot 4$ and $36.5,37.5$ and $36 \cdot 4,37.3$ and $35.8,37.0$ and 38.1 and 37.7 and $33.5 \mathrm{kDa}$. Lane $\mathrm{M}$, molecular mass standards. 
OmpH was most pronounced in OMP-types 6.1 and 6.2 $(33.5 \mathrm{kDa})$. Comparative analysis of the deduced amino acid sequences of the $\mathrm{OmpH}$ protein in somatic serotype strains of $P$. multocida has indicated that molecular mass heterogeneity is due to variation in the number of amino acids in two discrete hypervariable regions that are thought to correspond to external surface-exposed loops (Luo et al., 1999). Molecular mass heterogeneity also occurs in the corresponding $\mathrm{P} 2(\mathrm{OmpH})$ and $\mathrm{P} 5(\mathrm{OmpA})$ proteins of Haemophilus influenzae and is also due to differences in the size of hypervariable surface-exposed loop regions (Sikkema \& Murphy, 1992; Duim et al., 1997). These surface-exposed loops are thought to interact with the host immune system and, by undergoing antigenic variation, provide the bacterium with an important defence mechanism (Yi \& Murphy, 1997; Neary et al., 2001). The observed heterogeneity of the OmpA and OmpH proteins of porcine $P$. multocida strains might also be due to variation in the size of hypervariable surface-exposed loop regions and might play important roles in the pathogenesis of pneumonic pasteurellosis and PAR.

Eighteen groups of strains were identified based on specific combinations of OMP-type, capsular type and toxA status (Table 1). Strains representing each of these groups have most likely been derived from a common ancestral cell and are considered here to belong to the same clonal group. Preliminary sequence data from three housekeeping genes ( $a d k, g 6 p d$ and $m d h$ ) confirm the clonal nature of porcine $P$. multocida strains (unpublished data). Avian P. multocida strains have been shown to have a clonal population structure by multilocus enzyme electrophoresis (Blackall et al., 1998) and the association of specific OMP and lipopolysaccharide types was considered to mark clones of porcine strains of $P$. multocida (Lugtenberg et al., 1984). Our data provide strong evidence to suggest that different subpopulations (clones) of P. multocida are responsible for pneumonia and PAR in pigs. The majority ( $75 \%)$ of cases of pneumonia were associated exclusively with capsular type A strains of OMP-types 1.1, $2.1,3.1$ and 5.1. Notably, the toxA gene was absent from all of these strains. In addition, a small proportion (13\%) of pneumonia cases were caused by non-toxigenic capsular type D strains of OMP-type 6.1. In contrast, the majority (76\%) of cases of PAR were associated with toxA-containing capsular type D strains of OMP-type 4.1 and capsular type A and D strains of OMP-type 6.1. The association of capsular type D strains of OMP-type 6.1 with PAR or pneumonia was strongly correlated with the presence or absence, respectively, of the toxA gene. A strong correlation between PAR and possession of the toxA gene has been well documented in previous studies (Eamens et al., 1988; Gardner et al., 1994; Lariviere et al., 1992; Fussing et al., 1999; Sakano et al., 1992).

There have been very few studies of the molecular epidemiology of porcine pasteurellosis, which is poorly understood (Zhao et al., 1992; Blackall et al., 2000). Predominant restriction endonuclease analysis patterns or ribotypes have been described among $P$. multocida strains associated with pneumonia (Rubies et al., 2002; Zhao et al., 1992; Bowles et al., 2000; Blackall et al., 2000) and PAR (Gardner et al., 1994;
Fussing et al., 1999) but, in some cases, these may be associated with the nature of pig production (Rubies et al., 2002; Bowles et al., 2000; Blackall et al., 2000). A characteristic feature of most pathogenic bacteria is that the majority of cases of infectious disease are normally caused by a small number of clones (Selander \& Musser, 1990). Conversely, opportunistic infections are often associated with nonpathogenic strains that have a high level of diversity (Whittam, 1995; White et al., 1990). Pneumonic pasteurellosis is often considered to be a secondary infection, which follows initial infection with micro-organisms such as pseudorabies virus and M. hyopneumoniae (Ciprian et al., 1988; Fuentes \& Pijoan, 1987). Djordjevic et al. (1998) suggested that pneumonic $P$. multocida isolates are opportunistic pathogens of low virulence, although these authors based their conclusion on a study of only 10 strains isolated from lung lesions. In the present study, the majority ( $88 \%)$ of cases of porcine pneumonia were associated with nontoxigenic capsular type A strains of OMP-types 1.1, 2.1, 3.1 and 5.1 and non-toxigenic capsular type D strains of OMPtype 6.1. In particular, 57 (46\%) strains recovered from cases of pneumonia were of OMP-type 1.1. Furthermore, the strains studied in this investigation were isolated from widespread geographical locations in England and Wales over a 12-year period and represented mostly single sporadic cases.

We suggest two hypotheses to account for the limited diversity among $P$. multocida strains associated with porcine pneumonia in England and Wales. Firstly, the diversity of commensal strains occupying the nasopharynx of healthy pigs is relatively low. Strains isolated from diseased animals are opportunistic pathogens that have low diversity because they represent the normal background flora of the porcine nasopharynx. Secondly, the diversity of commensal strains occupying the nasopharynx of healthy pigs is relatively high. In this case, strains isolated from infected animals have low diversity because they represent a small number of virulent clones that are capable of causing disease under certain circumstances. The second scenario implies that $P$. multocida is not a secondary or opportunistic pathogen, as is generally considered, but instead has a primary role in the pathogenesis of porcine pneumonia. Examination of these hypotheses will require further characterization of $P$. multocida isolates representing the normal flora of the porcine nasopharynx.

The toxA gene was not distributed randomly among $P$. multocida strains, but was associated exclusively with capsular type A strains of OMP-types 6.1 and 6.2 and capsular type D strains of OMP-types 4.1 and 6.1 (Table 1). These findings support the view that distinct combinations of capsular types, toxA status and OMP-types represent clones of $P$. multocida. Toxigenic strains of capsular type A are relatively uncommon, although they are sometimes associated with outbreaks of PAR (Sakano et al., 1992) and pneumonia (Fussing et al., 1999; Choi et al., 2001). Our data show that toxigenic capsular type A strains represent two closely related but distinct clonal groups of $P$. multocida that are characterized by OMP-types 6.1 and 6.2. Clearly, 
toxigenic capsular type A strains of OMP-types 6.1 and 6.2 represent a subpopulation of $P$. multocida that is distinct from the non-toxigenic capsular type A strains of OMP-types $1.1,2.1,3.1$ and 5.1 associated mainly with pneumonia (Table 1).

Strains of OMP-types 1.1, 2.1, 3.1 and 5.1 were associated only with capsular type A, whereas isolates of OMP-types 1.2, 4.1, 4.2, 6.1 and 6.2 were associated with capsular types A and $\mathrm{D}$ (Table 1). The most likely explanation for these observations is that capsular switching, possibly involving horizontal transfer of capsular biosynthesis genes, has occurred among strains of the latter, but not the former, OMP-types (Musser et al., 1988). Toxigenic capsular type D strains of OMP-type 6.1 may also have been derived from non-toxigenic capsular type D strains of OMP-type 6.1 by horizontal transfer of the toxA gene. The association of toxA with capsular type $\mathrm{D}$ in the majority of the toxA-containing strains also suggests that the toxA gene is in linkage disequilibrium with the type $\mathrm{D}$ capsular gene cluster. In particular, the existence of toxAcontaining capsular type D strains of OMP-type 4.1 suggests that both the toxA and type $\mathrm{D}$ capsular genes may have been acquired by horizontal gene transfer in these isolates. The absence of both toxA and the type $\mathrm{D}$ capsule in pneumonic strains of OMP-types 1.1, 2.1, 3.1 and 5.1 (which comprise $82 \%$ of the isolates) suggests that these isolates are not susceptible to the horizontal transfer of these genes. Therefore, our data suggest that horizontal transfer of the tox $A$ and capsular biosynthesis genes is restricted mainly to specific subpopulations of $P$. multocida represented by OMP-types 4.1 and 4.2 and 6.1 and 6.2. It is interesting to speculate that strains representing these OMP-types have fundamental differences in their biology, with respect to horizontal transfer of the toxA and capsular genes, in comparison with isolates of OMP-types 1.1, 2.1, 3.1 and 5.1. One explanation that may account for these observations is that these two groups of strains occupy different ecological niches within the porcine respiratory tract and are effectively isolated from each other.

Gardner et al. (1994) identified toxigenic and non-toxigenic strains among isolates of the same genotype and suggested that lysogenic phage might account for their observations. These authors also identified a single toxigenic, capsular type A strain and suggested that the toxA gene may have been derived from a capsular type $D$ strain. A variety of toxin genes expressed by pathogenic bacteria are carried and transferred by bacteriophages (Cheetham \& Katz, 1995) and various lines of evidence suggest that phage-mediated transduction might also represent the mechanism of horizontal transfer of toxA in P. multocida. Nielsen \& Rosdahl (1990) isolated 24 different bacteriophages from porcine strains of $P$. multocida for typing toxigenic and non-toxigenic strains. Flanking sequences of toxA were shown to be homologous with bacteriophages isolated from $P$. multocida, and induction of toxigenic strains yielded DNA fragments that hybridized with a toxA probe (Andresen et al., 1990). It has also been suggested that phage conversion is responsible for the generation of a particular ribotype that is itself associated with toxin production (Donnio et al., 1999).

In summary, this study has demonstrated that different subpopulations of $P$. multocida are responsible for pneumonia and PAR in pigs. The association of a small number of clones with porcine pneumonia in England and Wales suggests that these strains are not opportunistic pathogens, but are virulent isolates that have a primary role in the pathogenesis of this disease. The association of both capsular types $\mathrm{A}$ and $\mathrm{D}$, and the toxA gene, with a small number of specific OMP-types in strains associated primarily with PAR suggests that horizontal transfer of capsular biosynthesis and toxA genes has occurred among these isolates.

\section{ACKNOWLEDGEMENTS}

This study was supported by a Wellcome Trust University Award to R. L. D. (053669/Z/98/Z). We are grateful to staff of the VLA for the provision of isolates, including those at Bury St Edmunds for making available strains of their $P$. multocida collection.

\section{REFERENCES}

Andresen, L. O., Petersen, S. K., Christiansen, C. \& Nielsen, J. P. (1990). Studies on the location of the Pasteurella multocida toxin gene toxA. In Proceedings of the Eleventh International Pig Conference, p. 60. Lausanne, Switzerland.

Beher, M. G., Schnaitman, C. A. \& Pugsley, A. P. (1980). Major heatmodifiable outer membrane protein in Gram-negative bacteria: comparison with the OmpA protein of Escherichia coli. J Bacteriol 143, 906-913.

Blackall, P. J., Fegan, N., Chew, G. T. I. \& Hampson, D. J. (1998). Population structure and diversity of avian isolates of Pasteurella multocida from Australia. Microbiology 144, 279-289.

Blackall, P. J., Fegan, N., Pahoff, J. L. \& 8 other authors (2000). The molecular epidemiology of four outbreaks of porcine pasteurellosis. Vet Microbiol 72, 111-120.

Bowersock, T. L., Hooper, T. \& Pottenger, R. (1992). Use of ELISA to detect toxigenic Pasteurella multocida in atrophic rhinitis in swine. J Vet Diagn Invest 4, 419-422.

Bowles, R. E., Pahoff, J. L., Smith, B. N. \& Blackall, P. J. (2000). Ribotype diversity of porcine Pasteurella multocida from Australia. Aust Vet J 78, 630-635.

Buys, W. E., Smith, H. E., Kamps, A. M., Kamp, E. M. \& Smits, M. A. (1990). Sequence of the dermonecrotic toxin of Pasteurella multocida ssp. multocida. Nucleic Acids Res 18, 2815-2816.

Chanter, N. \& Rutter, J. M. (1989). Pasteurellosis in pigs and the determinants of virulence of toxigenic Pasteurella multocida. In Pasteurella and Pasteurellosis, pp. 161-195. Edited by C. F. Adlam \& J. M. Rutter. London: Academic Press.

Cheetham, B. F. \& Katz, M. E. (1995). A role for bacteriophages in the evolution and transfer of bacterial virulence determinants. Mol Microbiol 18, 201-208.

Choi, C., Kim, B., Cho, W.-S., Kim, J., Kwon, D., Cheon, D.-S. \& Chae, C. (2001). Capsular serotype, toxA gene, and antimicrobial susceptibility profiles of Pasteurella multocida isolated from pigs with pneumonia in Korea. Vet Rec 149, 210-212.

Ciprian, A., Pijoan, C., Cruz, T., Camacho, J., Tortora, J., Colmenares, 
G., Lopez-Revilla, R. \& de la Garza, M. (1988). Mycoplasma hyopneumoniae increases the susceptibility of pigs to experimental Pasteurella multocida pneumonia. Can J Vet Res 52, 434-438.

Davies, R. L. \& Donachie, W. (1996). Intra-specific diversity and host specificity within Pasteurella haemolytica based on variation of capsular polysaccharide, lipopolysaccharide and outer-membrane proteins. Microbiology 142, 1895-1907.

Davies, R. L., Parton, R., Coote, J. G., Gibbs, H. A. \& Freer, J. H. (1992). Outer-membrane protein and lipopolysaccharide variation in Pasteurella haemolytica serotype A1 under different growth conditions. J Gen Microbiol 138, 909-922.

Davies, R. L., MacCorquodale, R. \& Caffrey, B. (2003). Diversity of avian Pasteurella multocida strains based on capsular PCR typing and variation of the OmpA and $\mathrm{OmpH}$ outer membrane proteins. Vet Microbiol 91, 169-182.

Djordjevic, S. P., Eamens, G. J., Ha, H., Walker, M. J. \& Chin, J. C. (1998). Demonstration that Australian Pasteurella multocida isolates from sporadic outbreaks of porcine pneumonia are non-toxigenic (toxA-) and display heterogeneous DNA restriction endonuclease profiles compared with toxigenic isolates from herds with progressive atrophic rhinitis. J Med Microbiol 47, 679-688.

Donnio, P. Y., Allardet-Servent, A., Perrin, M., Escande, F. \& Avril, J. L. (1999). Characterisation of dermonecrotic toxin-producing strains of Pasteurella multocida subsp. multocida isolated from man and swine. J Med Microbiol 48, 125-131.

Duim, B., Bowler, L. D., Eijk, P. P., Jansen, H. M., Dankert, J. \& Van Alphen, L. (1997). Molecular variation in the major outer membrane protein P5 gene of nonencapsulated Haemophilus influenzae during chronic infections. Infect Immun 65, 1351-1356.

Eamens, G. J., Kirkland, P. D., Turner, M. J., Gardner, I. A., White, M. P. \& Hornitzky, C. L. (1988). Identification of toxigenic Pasteurella multocida in atrophic rhinitis of pigs by in vitro characterisation. Aust Vet J 65, $120-123$.

Foged, N. T., Nielsen, J. P. \& Pedersen, K. B. (1988). Differentiation of toxigenic from nontoxigenic isolates of Pasteurella multocida by enzyme-linked immunosorbent assay. J Clin Microbiol 26, 1419-1420.

Fuentes, M. C. \& Pijoan, C. (1987). Pneumonia in pigs induced by intranasal challenge exposure with pseudorabies virus and Pasteurella multocida. Am J Vet Res 48, 1446-1448.

Fussing, V., Nielsen, J. P., Bisgaard, M. \& Meyling, A. (1999). Development of a typing system for epidemiological studies of porcine toxinproducing Pasteurella multocida ssp. multocida in Denmark. Vet Microbiol 65, 61-74

Gardner, I. A., Kasten, R., Eamens, G. J., Snipes, K. P. \& Anderson, R. J. (1994). Molecular fingerprinting of Pasteurella multocida associated with progressive atrophic rhinitis in swine herds. J Vet Diagn Invest 6, 442-447.

Harel, J., Cote, S. \& Jacques, M. (1990). Restriction endonuclease analysis of porcine Pasteurella multocida isolates from Quebec. Can J Vet Res 54, 422-426.

Kamp, E. M. \& Kimman, T. G. (1988). Induction of nasal turbinate atrophy in germ-free pigs, using Pasteurella multocida as well as bacterium-free crude and purified dermonecrotic toxin of $P$. multocida. Am J Vet Res 49, 1844-1849.

Laemmli, U. K. (1970). Cleavage of structural proteins during the assembly of the head of bacteriophage T4. Nature 227, 680-685.

Lariviere, S., Leblanc, L., Mittal, K. R. \& Martineau, G. P. (1992). Characterization of Pasteurella multocida from nasal cavities of piglets from farms with or without atrophic rhinitis. J Clin Microbiol 30, $1398-1401$.
Lax, A. J., Chanter, N., Pullinger, G. D., Higgins, T., Staddon, J. M. \& Rozengurt, E. (1990). Sequence analysis of the potent mitogenic toxin of Pasteurella multocida. FEBS Lett 277, 59-64.

Lichtensteiger, C. A., Steenbergen, S. M., Lee, R. M., Polson, D. D. \& Vimr, E. R. (1996). Direct PCR analysis for toxigenic Pasteurella multocida. J Clin Microbiol 34, 3035-3039.

Lin, J., Huang, S. \& Zhang, Q. (2002). Outer membrane proteins: key players for bacterial adaptation in host niches. Microbes Infect 4, $325-331$.

Lugtenberg, B., Van Boxtel, R. \& De Jong, M. (1984). Atrophic rhinitis in swine: correlation of Pasteurella multocida pathogenicity with membrane protein and lipopolysaccharide patterns. Infect Immun $\mathbf{4 6}$ $48-54$.

Luo, Y., Glisson, J. R., Jackwood, M. W., Hancock, R. E. W., Bains, M., Cheng, I. H. \& Wang, C. (1997). Cloning and characterization of the major outer membrane protein gene $(\mathrm{ompH})$ of Pasteurella multocida X-73. J Bacteriol 179, 7856-7864.

Luo, Y., Zeng, Q., Glisson, J. R., Jackwood, M. W., Cheng, I. H. \& Wang, C. (1999). Sequence analysis of Pasteurella multocida major outer membrane protein $(\mathrm{OmpH})$ and application of synthetic peptides in vaccination of chickens against homologous strain challenge. Vaccine 17, 821-831.

Markwell, M. A. K., Haas, S. M., Bieber, L. L. \& Tolbert, N. E. (1978). A modification of the Lowry procedure to simplify protein determination in membrane and lipoprotein samples. Anal Biochem 87, 206-210.

Musser, J. M., Kroll, J. S., Moxon, E. R. \& Selander, R. K. (1988). Evolutionary genetics of the encapsulated strains of Haemophilus influenzae. Proc Natl Acad Sci U S A 85, 7758-7762.

Neary, J. M., Yi, K., Karalus, R. J. \& Murphy, T. F. (2001). Antibodies to loop 6 of the P2 porin protein of nontypeable Haemophilus influenzae are bactericidal against multiple strains. Infect Immun 69, 773-778.

Nielsen, J. P. \& RosdahI, V. T. (1990). Development and epidemiological applications of a bacteriophage typing system for typing Pasteurella multocida. J Clin Microbiol 28, 103-107.

Petersen, S. K. (1990). The complete nucleotide sequence of the Pasteurella multocida toxin gene and evidence for a transcriptional repressor, TxaR. Mol Microbiol 4, 821-830.

Pijoan, C. (1992). Pneumonic pasteurellosis. In Diseases of Swine, 7th edn, pp. 552-559. Edited by A. D. Leman, B. E. Straw, W. L. Mengeling, S. D’Alliare \& D. J. Taylor. Ames, IA: Iowa State University Press.

Pijoan, C. \& Fuentes, M. (1987). Severe pleuritis associated with certain strains of Pasteurella multocida in swine. J Am Vet Med Assoc 191, $823-826$

Pijoan, C., Morrison, R. B. \& Hilley, H. D. (1983). Serotyping of Pasteurella multocida isolated from swine lungs collected at slaughter. J Clin Microbiol 17, 1074-1076.

Pijoan, C., Lastra, A., Ramirez, C. \& Leman, A. D. (1984). Isolation of toxigenic strains of Pasteurella multocida from lungs of pneumonic swine. J Am Vet Med Assoc 185, 522-523.

Rhoades, K. R. \& Rimler, R. B. (1987). Capsular groups of Pasteurella multocida isolated from avian hosts. Avian Dis 31, 895-898.

Rimler, R. B. \& Rhoades, K. R. (1987). Serogroup F, a new capsule serogroup of Pasteurella multocida. J Clin Microbiol 25, 615-618.

Rosenbusch, J. P. (1974). Characterization of the major envelope protein from Escherichia coli. Regular arrangement on the peptidoglycan and unusual dodecyl sulfate binding. J Biol Chem 249, 8019-8029.

Rubies, X., Casal, J. \& Pijoan, C. (2002). Plasmid and restriction endonuclease patterns in Pasteurella multocida isolated from a swine pyramid. Vet Microbiol 84, 69-78. 
Sakano, T., Taneda, A., Okada, M., Ono, M., Hayashi, Y. \& Sato, S. (1992). Toxigenic type A Pasteurella multocida as a causative agent of nasal turbinate atrophy in swine. J Vet Med Sci 54, 403-407.

Selander, R. K. \& Musser, J. M. (1990). Population genetics of bacterial pathogenesis. In Molecular Basis of Bacterial Pathogenesis, pp. 11-36. Edited by B. H. Iglewski \& V. L. Clark. San Diego: Academic Press.

Sikkema, D. J. \& Murphy, T. F. (1992). Molecular analysis of the $\mathrm{P} 2$ porin protein of nontypeable Haemophilus influenzae. Infect Immun 60, 5204-5211.

Townsend, K. M., Boyce, J. D., Chung, J. Y., Frost, A. J. \& Adler, B. (2001). Genetic organization of Pasteurella multocida cap loci and development of a multiplex capsular PCR typing system. J Clin Microbiol 39, 924-929.

Vasfi Marandi, M. \& Mittal, K. R. (1995). Identification and characterization of outer membrane proteins of Pasteurella multocida serotype D by using monoclonal antibodies. J Clin Microbiol 33, 952-957.

Vasfi Marandi, M. \& Mittal, K. R. (1996). Characterization of an outer membrane protein of Pasteurella multocida belonging to the OmpA family. Vet Microbiol 53, 303-314.

Vasfi Marandi, M. \& Mittal, K. R. (1997). Role of outer membrane protein $\mathrm{H}(\mathrm{OmpH})$ - and OmpA-specific monoclonal antibodies from hybridoma tumors in protection of mice against Pasteurella multocida. Infect Immun 65, 4502-4508.
Vasfi Marandi, M., Dubreuil, J. D. \& Mittal, K. R. (1996). The $32 \mathrm{kDa}$ major outer-membrane protein of Pasteurella multocida capsular serotype D. Microbiology 142, 199-206.

White, D. G., Wilson, R. A., Gabriel, A. S., Saco, M. \& Whittam, T. S. (1990). Genetic relationships among strains of avian Escherichia coli associated with swollen-head syndrome. Infect Immun 58, 3613-3620.

Whittam, T. S. (1995). Genetic population structure and pathogenicity in enteric bacteria. In Population Genetics of Bacteria (Society for General Microbiology Symposium no. 52), pp. 217-245. Edited by S. Baumberg, J. P. W. Young, E. M. H. Wellington \& J. R. Saunders. Cambridge: Cambridge University Press.

Wilson, M. A., Morgan, M. J. \& Barger, G. E. (1993). Comparison of DNA fingerprinting and serotyping for identification of avian Pasteurella multocida isolates. J Clin Microbiol 31, 255-259.

Yi, K. \& Murphy, T. F. (1997). Importance of an immunodominant surface-exposed loop on outer membrane protein P2 of nontypeable Haemophilus influenzae. Infect Immun 65, 150-155.

Zhao, G., Pijoan, C., Murtaugh, M. P. \& Molitor, T. W. (1992). Use of restriction endonuclease analysis and ribotyping to study epidemiology of Pasteurella multocida in closed swine herds. Infect Immun 60, 1401-1405. 